\title{
Cellular Physiology of the Turtle Visual Cortex: Distinctive Properties of Pyramidal and Stellate Neurons
}

\author{
Barry W. Connors and Arnold R. Kriegstein \\ Department of Neurology, Stanford University School of Medicine, Stanford, California 94305
}

The electrophysiological properties of neurons in the three-layered dorsal cortex of the turtle, Pseudemys scripta elegans, have been studied in vitro. Intracellular recordings suggested two distinct classes of neuronal behavior. Cell labeling with either Lucifer Yellow or horseradish peroxidase revealed that these behaviors correlated with the two morphological classes of cortical neurons: pyramidal cells and stellate cells. Examination of Golgi-stained neurons of dorsal cortex did not uncover any other obvious classes.

Pyramidal cells had their somata in the cell layer, and extended several densely spined apical dendrites through the molecular layer to the pia. They also had spiny basilar dendrites directed through the subcellular layer toward the ependymal border. Physiologically, pyramidal cells had relatively prolonged action potentials that showed marked frequency adaptation during a sustained suprathreshold current pulse. Their most striking characteristic was a tendency to fire two discrete sizes of action potential, one small (mean $=34 \mathrm{mV}$ ) and of relatively low threshold, the other large (mean $=76 \mathrm{mV}$ ) and of higher threshold. We hypothesize that at least some small spikes arise from distal dendritic sites, whereas large spikes are somatically generated. Both spikes were tetrodotoxin-sensitive, although calcium-dependent electrogenesis occurred when potassium channels were blocked. In contrast to pyramidal cells, the somata of stellate cells were found in the molecular and subcellular zones. Their dendrites tended to be horizontally oriented and spine-free. Stellate cells had relatively brief action potentials, each of which was followed by a large but short-lasting undershoot of membrane potential. Stellate cells showed little or no spike frequency adaptation. Spike amplitudes were always relatively uniform and large (mean $=73 \mathrm{mV}$ ). Thus, in the dorsal cortex of turtles, the pyramidal cells, which are projection neurons, and stellate cells, which are local GABAergic inhibitory neurons, have distinctly different membrane characteristics. The physiological properties of the two types of turtle cortical neurons are very similar to their counterparts in cortical structures of the mammalian telencephalon.

The comparative approach to neurobiology has provided useful clues about phylogenetic relationships and the morphological and functional adaptations of the nervous system. Cortical struc-

Received Apr. 2, 1985; revised July 8, 1985; accepted July 11, 1985

We thank Robert E. Foster for introducing us to the turtle cortex, Itzhak Fried for preparing the Golgi stains, Bruce R. Ransom for participating in some of the early experiments, and K. L. Chow, P. H. Desan, and D. A. McCormick for critical comments on the manuscript. We also acknowledge the excellent technical assistance of Suzanne Lyon and Jay Kadis, and manuscript preparation by Marie Holt and Cheryl Joo. These studies were supported by The Klingenstein Fund and NIH Grants NS 12151, NS 00887, and NS 21223.

Correspondence should be addressed to Barry W. Connors, Ph.D., Department of Neurology, Stanford University Medical Center, Stanford, CA 94305.

Copyright (C) 1986 Society for Neuroscience $0270-6474 / 86 / 010164-14 \$ 02.00 / 0$ tures of the telencephalon have been extensively studied in a wide range of species (for reviews, see Diamond and Hall, 1969; Northcutt, 1981; Ulinski, 1983); however the vast majority of these investigations have been concerned with anatomical questions. Similarly, most of the studies using electrophysiological techniques have nevertheless been "electroanatomical" in nature (Belekhova, 1979), in that evoked activity was used to determine patterns of connections. Detailed physiological studies of cortical cell properties and intrinsic synaptic circuitry have been confined to only a few species of higher mammals (for reviews, see Jones and Peters, 1984; McCormick et al., 1985; Stafstrom et al., 1984). In contrast, extensive comparative surveys of cerebellar (Llinas, 1969), retinal (Dowling, 1970) and, to a lesser extent, spinal cord (Simpson, 1976) neurophysiology have been performed. The success of these efforts has prompted us to examine the cellular physiology of the relatively simple dorsal (or general) cortex of the turtle, Pseudemys scripta elegans.

Dorsal cortex is the visual cortex of many reptiles, though it may also subscrve other sensory modalities. There are several compelling reasons for studying the turtle dorsal cortex. The order Chelonia, of which turtles are the only living examples, is thought to have diverged directly from cotylosaurs, the basic stock from which all reptiles (and therefore mammals) have descended; further, turtles have changed little from their ancestral forms of the Triassic period (Romer, 1972). The anatomy of turtle cortex has been illuminated by many elegant studies. Turtle dorsal cortex and mammalian neocortex share several important afferent connections, including the distribution of thalamic, adrenergic, and cholinergic inputs (Desan, 1984; Hall and Ebner, 1970; Hall et al., 1977; Hohmann et al., 1983; Ouimet and Ebner, 1981; Parent and Poitras, 1974; Smith et al., 1980). Both cortices also share similar efferent connections to the thalamus and brainstem (Hall et al., 1977). While there is currently no consensus regarding evolutionary homologies among cortical structures, detailed physiological studies can contribute by defining the similarities and differences between species with a common ancestry.

Although the extrinsic connectivity of the turtle dorsal cortex resembles neocortex, the intracortical structure of the turtle is greatly simplified compared to that of the mammal. Instead of a six-layered isocortex, the turtle has only three cortical layers, with two general classes of neurons: pyramidal cells that form the main output of the cortex, and stellate interneurons (Balaban, 1978; Davydova and Goncharova, 1979; Desan, 1984; Northcutt, 1970; Ramon, 1896; Ramon y Cajal, 1911). The pyramidal cells are arrayed in a single perikaryal lamina. They have long, spine-bearing apical dendrites that ascend to the superficial molecular layer, and basilar dendrites extending into a subcellular zone. Their spine morphologies are similar to those described for pyramidal cells of mammalian somatosensory cortex (Jones and Powell, 1969). Stellate cells generally reside in 
the molecular and subcellular layers, and have aspinous or sparsely spined dendrites that are mostly oriented parallel to the pial surface.

The turtle brain has distinct advantages for physiological experiments. Its neurons are relatively large, making routine intracellular recording possible. More uniquely, the freshwater diving turtles chosen for study have the ability to function under conditions of prolonged hypoxia (Belkin, 1963; Sick et al., 1982). This attribute simplifies the maintenance of large portions of the intact cerebral cortex in vitro.

Thus, turtle dorsal cortex is of great phylogenetic interest; it is relatively simple and anatomically well-described; and it has clear practical advantages. This paper describes the distinctive electrophysiological and morphological properties of pyramidal and stellate cells, while the following paper (Kriegstein and Connors, 1986) details some of the synaptic physiology of the cortical circuitry. Some of these results have been presented in abstract form (Connors et al., 1983; Kriegstein and Connors, 1984).

\section{Materials and Methods}

\section{Dissection and maintenance in vitro}

Experiments were performed on the dorsal (or general) cortex from adult (shells 20-30 cm long) specimens of the red-eared turtle Pseudemys scripta elegans obtained from Delta Biological Limited, Vidalia, LA. Some authors now include this species within the genus Chrysemys, but this classification is controversial (Harless and Morlock, 1979) and the older term will be retained here because it is embedded in the neurobiological literature. Figure $1 A$ schematically illustrates the area of cortex under study. The shaded area of the dorsal view on the right represents the approximate limits of the cortex displaying evoked potentials to sensory stimuli (Belekhova, 1979). Nissl-stained sections (Fig. 1B) illustrate the three-layered organization of the general cortex, including the wide but cell-sparse molecular layer, the densely packed cell layer, and the narrow subcellular layer. A sheet of ependymal cell bodies lines the ventricular surface.

Turtles were decapitated, the brains removed, and the dorsal area of cortex dissected free from each hemisphere. This provided a cortical fragment approximately $10 \mathrm{~mm}$ square and slightly less than $1 \mathrm{~mm}$ thick. One piece of cortex was placed with the ventricular surface upward in a recording chamber, where it was continuously superfused with saline (Mori et al., 1981) containing (in $\mathrm{mm}$ ) $\mathrm{NaCl}, 96.5 ; \mathrm{KCl}, 2.6 ; \mathrm{CaCl}_{2}, 4.0$; $\mathrm{MgCl}, 2.0 ; \mathrm{NaHCO}_{3}, 31.5$; dextrose, 10 ; and saturated with $95 \% \mathrm{O}_{2}$ and $5 \% \mathrm{CO}_{2}$ gas ( $\left.\mathrm{pH} 7.4\right)$. All experiments were carried out at room temperature (about $22^{\circ} \mathrm{C}$ ). We found the turtle cortex to be quite hardy, and cortical specimens were occasionally stored at $4^{\circ} \mathrm{C}$ for $18 \mathrm{hr}$ prior to use with no apparent detrimental effects.

\section{Electrophysiological techniques}

Intracellular recordings from nonlabeled cells were made with glass microelectrodes filled with either $3 \mathrm{~m} \mathrm{~K}$ acetate or $3 \mathrm{~m} \mathrm{KCl}$. Electrodes had resistances between 30 and $100 \mathrm{M} \Omega$. Current was injected through the recording electrode via an active bridge circuit, and balance was continually adjusted by canceling the rapid voltage jump at the onset and offset of the current pulse (Engle et al., 1972). The signal was amplified and recorded on magnetic tape (DC to $5 \mathrm{kHz}$ ). Extracellular recordings were made with micropipettes filled with $1 \mathrm{M} \mathrm{NaCl}$ and broken to resistances of 3-5 M . Focal extracellular stimulation was applied through sharpened bipolar or monopolar tungsten electrodes that were insulated to within $10 \mu \mathrm{m}$ of the tip. Single cathodal pulses (200 $\mu$ sec duration) were applied to the ependymal surface. In some cases, substances were focally applied to the cortex by pressure pulses to a broken micropipette. Some of the data were digitized and analyzed off-line on a MINC-23 computer (Digital Equipment Corp.).

\section{Intracellular labeling}

For those experiments in which cells were labeled with HRP, animals were first anesthetized with a subdermal injection of sodium pentobarbital $(37 \mathrm{mg} / \mathrm{kg})$ and immersed in an ice-water bath for $60 \mathrm{~min}$. The plastron was then cut away and ice cold turtle saline was perfused intracardially prior to decapitation. This procedure eliminated nonspe-
A

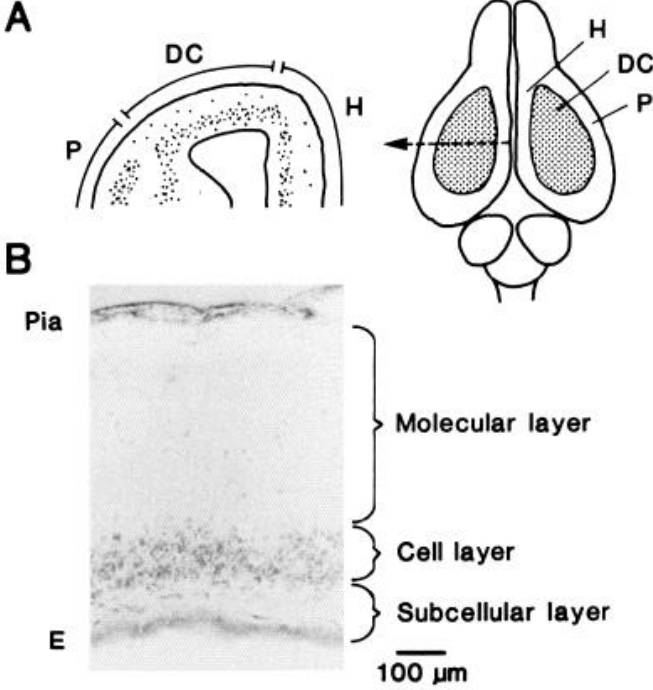

Figure 1. Basic structure of the turtle dorsal cortex. A, Schematic drawing depicting the visual cortex of the turtle brain (adapted from Volanschi and Servit, 1969). In the right-hand panel, the visual cortices are shown as stippled regions on the cerebral hemispheres. The lefthand panel depicts the dorsal half of a coronal section at the level of the dashed line shown on the right. The cortex is bordered by the pial membrane dorsally and by the ependymal surface ventrally. $H=$ hippocampus, $D C=$ dorsal cortex, $P=$ pyriform cortex. $B$, A cresyl violetstained section of the visual cortex cut coronally. The three layers are labeled, and the ependymal layer $(E)$ is on the bottom.

cific staining of blood cells during processing for HRP. Microelectrodes were made from glass capillary tubes with internal fibers (WP Instruments, Inc., New Haven, CT) filled with 3\% HRP (Sigma, Type VI) and beveled to resistances of 50-150 M . HRP was ejected by applying depolarizing current pulses of 2-5 nA for $250-500 \mathrm{msec}$ duration at a frequency of $1-2 \mathrm{~Hz}$ for at least $5 \mathrm{~min}$. Tissue labeled with HRP was immersion-fixed in $2 \%$ glutaraldehyde- $2 \%$ paraformaldehyde, rinsed in phosphate buffer, and processed via a cobalt-intensified diaminobenzidine method, as described elsewhere (Kitai and Bishop, 1981). Some cortical slabs containing HRP-filled cells were first mounted intact on slides; the HRP-filled cells were drawn and photographed in wholemount; and the cortex subsequently embedded and sectioned serially at right angles to the pia for viewing and reconstruction of neurons in cross section.

When cells were labeled with Lucifer Yellow (LY; Stewart, 1978), microelectrodes were filled with $3 \% \mathrm{LY}$ in $2 \mathrm{M} \mathrm{LiCl}$, and beveled to resistances of 50-150 M . LY was iontophoretically ejected by 3-4 nA hyperpolarizing current pulses or steady hyperpolarizing current for 3$10 \mathrm{~min}$. Tissue containing LY-filled cells was fixed in $4 \%$ buffered formalin overnight and then dehydrated through graded alcohols and cleared and mounted in methylsalicylate. LY-filled cells were viewed and photographed under a Leitz Dialux 20 microscope equipped with epifluorescent filters (Leitz E3)

\section{Golgi staining}

Turtle visual cortex was prepared using a modification of the rapid Golgi method. Fixation was obtained by intracardiac perfusion of $10 \%$ buffered formalin. The brain was removed, bisected, and the rostral and caudal ends of one cerebral hemisphere were trimmed away. The resulting block of tissue was then immersed in osmium-dichromate solution and processed as described by Valverde (1970). The block was subsequently dehydrated in alcohol and embedded in paraffin for sectioning. Fifty-micron sections were cut on a sliding microtome and the tissue was cleared and mounted for inspection and photography, using a Leitz Dialux 20 microscope equipped with a vario-orthomat camera.

\section{Results}

Intracellular micropipettes easily penetrated the ventricular surface. The first cells to be encountered were usually ependymal cells, recognizable by their glial electrophysiological properties 

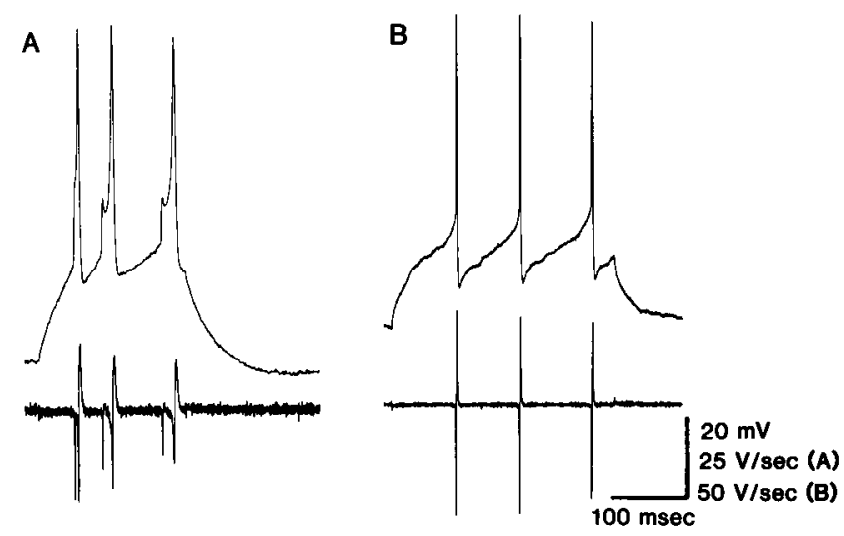

Figure 2. Action-potential characteristics of pyramidal and stellate cells. Upper traces are intracellular voltage responses to square current pulses; bottom traces are differentiated with respect to time. $A$, Response of a turtle pyramidal neuron to a square depolarizing intracellular-current pulse. The action potentials are relatively slow, with multiple spike amplitudes. The multiple components of the rising phases and the relatively slow falling phase of the action potentials are best observed in the differentiated trace. $B$, Response of a stellate cell to a depolarizing intracellular-current pulse. Note the faster action potentials, the relatively simple and symmetric rising and falling phases, the unitary amplitudes, and the prominent undershooting afterpotentials. Downwards in the differentiated traces is positive. Note the different calibrations for differentiated traces in $A$ and $B$.

(Connors and Ransom, 1982), i.e., high resting potentials (>90 $\mathrm{mV}$ ), very low input resistances, short time constants, and lack of intrinsic excitability or synaptic potentials. Within the next $200 \mu \mathrm{m}$ of tissue, neurons were impaled frequently. Cellular activity decreased substantially when the electrode tip passed beyond the cell layer and into the molecular layer.

\section{Correlation of physiological properties with morphology}

Neurons of the dorsal cortex could be unambiguously separated into two groups, based upon electrophysiological and morphological differences. The most commonly encountered cell was identifiable by its unique action potentials. Intracellularly applied pulses of depolarizing current generated action potentials of 2 or more discrete amplitudes in about $75 \%(n=44)$ of these cells. By far the most common pattern was a complex of two types of spikes, one relatively small (30-40 $\mathrm{mV}$ peak amplitude above resting potential) and of low threshold, and one larger (mean amplitude of $76.4 \mathrm{mV}$ above resting potential) with a higher threshold. Representative examples of this type of behavior are shown in Figures $2 A$ and $12 A$. The small action potentials usually preceded the larger ones, and often appeared to trigger them. Small spikes could sometimes be elicited in isolation (Fig. 12A, second set of traces). The minority of neurons (of this type) that had only one spike size always displayed the full-sized spike rather than the smaller one; in these cases it was usually possible to discriminate a prominent shoulder on the rising phase of the action potential. Differentiating the membrane voltage with respect to time shows this to best advantage. For example, the first action potential illustrated in Figure $2 \mathrm{~A}$ (top) has only one larger-amplitude peak. However, there is a distinct inflection point on its rising phase, and the differentiated trace (Fig. $2 A$, bottom) clearly shows two separate maxima in the rate of rise. It seems likely that, in these cases, a smaller action potential was evoked first, and it in turn triggered the larger action potential so rapidly that the small spike did not have time to begin repolarizing. During sustained suprathreshold stimuli, large spikes often separated into small and large components (Figs. $2 A$ and $5 A$ ). A small number of neurons
Table 1. Membrane properties of cortical neurons

\begin{tabular}{lcc} 
& Pyramidal & Stellate \\
\hline$V_{\mathrm{m}}(\mathrm{mV})$ & $63 \pm 12.9(30)$ & $61 \pm 11.0(6)$ \\
$R_{\mathrm{N}}(\mathrm{M} \Omega)$ & $83 \pm 39.6(38)$ & $86 \pm 28.1(6)$ \\
$\tau_{\mathrm{m}}(\mathrm{msec})$ & $140 \pm 62(21)$ & $51 \pm 10.7(5)^{*}$ \\
Full spike amplitude $(\mathrm{mV})$ & $76 \pm 10.5(32)$ & $73 \pm 13.5(6)$ \\
Full spike width $(\mathrm{msec})$ & $2.9 \pm 1.0(7)$ & $1.3 \pm 0.4(7)^{*}$ \\
Small spike amplitude $(\mathrm{mV})$ & $34 \pm 8.1(10)$ & - \\
$d V / d t_{\text {rise }}(V / \mathrm{sec})$ & $45 \pm 14.0(7)$ & $84 \pm 24.1(7)^{*}$ \\
$d V / d t_{\text {fall }}(V / \mathrm{sec})$ & $25 \pm 6.4(7)$ & $61 \pm 15.0(7)^{*}$ \\
Primary $f / I(\mathrm{~Hz} / \mathrm{nA})$ & $95 \pm 35(5)$ & $127 \pm 50(5)$
\end{tabular}

All data presented as mean \pm SD (number of cells). $V_{m}=$ resting membrane potential; $R_{\mathrm{N}}=$ input resistance; $\tau_{\mathrm{m}}=$ membrane time constant; $d V / d t_{\text {rixe }}=$ maximum rate of rise for full spike; $d V / d t_{\mathrm{tat}}=$ maximum rate of fall for full spike; full spike width $=$ spike duration at one-half amplitude measured from threshold to peak primary $f / I=$ slope of frequency/current relationship calculated from first interspike interval; ${ }^{*}=$ significant difference between stellates and pyramids, $p<0.002$ (twotailed Mann-Whitney $U$ test; all others not significantly different, $p>0.05$ ).

displayed three discrete spike sizes. Intracellular injections of LY or HRP revealed that the neurons described above were invariably pyramidal cells (see below).

The second type of neuron was encountered much less frequently. When stained with LY or HRP, it had one of several stellate forms. The action potentials of these cells differed from the spikes of pyramidal cells in a number of ways. Most notably, they had only a single, narrow range of amplitudes (Figs. $2 B$ and $5 B$ ), which was similar to that of the largest pyramidal cell spikes. The rising and falling phases were smooth, as reflected in the single positive and negative peaks of the first derivative of the action-potential waveform. Each action potential was followed by a very brief, but prominent, undershoot of voltage. Quantitatively, the unitary spikes of stellate cells had significantly higher rates of rise and fall and a much briefer duration than did the spikes of pyramidal cells (Table 1). The ranges of values for the latter three parameters showed no overlap between cell types. Thus, an intracellular recording of a few action potentials may reliably indicate the general morphological class of the neuron.

Some of the passive electrical properties of pyramidal and stellate neurons are summarized in Table 1 . Resting potential $\left(V_{\mathrm{m}}\right)$ was estimated from the voltage jump obtained upon withdrawal from the cell, and did not differ significantly between types. Input resistances $\left(R_{\mathrm{N}}\right)$ were also similar, and were obtained by passing saturatingly long pulses of 0.1 to $0.2 \mathrm{nA}$ through the recording electrode. As shown in Figure $3, A, B$, the currentvoltage relationships of pyramidal cells were usually quite linear. However, a minority of pyramidal cells displayed some degree of anomalous rectification, characterized by a pronounced sag in the voltage response to large hyperpolarizing currents (Fig. $3 C$ ). Displayed graphically, this indicates a decrease in slope resistance at potentials 20 to $40 \mathrm{mV}$ below rest (Fig. $3 D$ ). Too few stellate cells were tested in this way to allow comparison. Membrane time constants $\left(\tau_{\mathrm{m}}\right)$ were measured by applying square, hyperpolarizing currents to elicit a voltage deflection of less than $20 \mathrm{mV}$ (Fig. $4 A$ ). The onset of the voltage change was plotted semilogarithmically vs time, and $\tau_{\mathrm{m}}$ was estimated from the limiting slope of the relationship (Fig. 4B). As shown in Table 1 , stellate cells had significantly faster $\tau_{\mathrm{m}} \mathrm{s}$ than pyramidal cells.

The repetitive firing properties of stellate and pyramidal neurons were very distinctive. Both cell types could fire a sustained train of action potentials during a long, depolarizing current pulse (Fig. 5, $A, B$ ). The slope of the relationship between actionpotential frequency (calculated from the first interspike interval) and injected current intensity was somewhat higher for stellate 
A

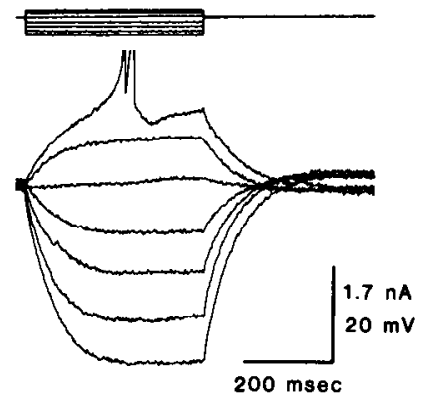

C

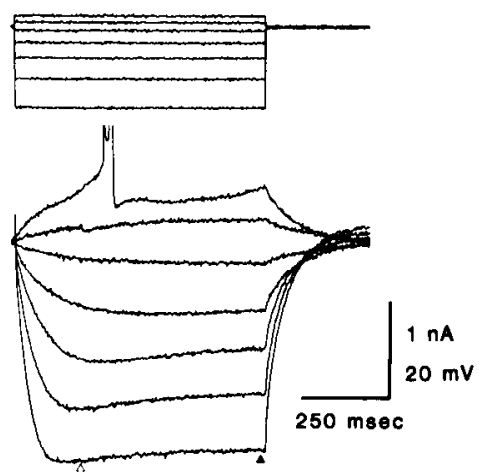

Figure 3. Current-voltage relationship for two pyramidal neurons. $A$, Current pulses of varying amplitudes (top traces) were passed through the microelectrode, and the resulting voltage deflections (bottom traces) were recorded. Action potentials have been truncated. $B$, Plot of current pulse amplitudes vs voltage defiection, measured just before the end of the pulse for the cell illustrated in $A$. The straight line represents a slope resistance of $118 \mathrm{M} \Omega$. $C$, Current voltage traces from a second neuron, showing anomalous rectification. Note the sag in the voltage response to large hyperpolarizing currents. Triangles at bottom point to the latencies at which measurements were made for $D$. $D$. Plot of data from $C$. Measurements were made at short (open symbols) and long (closed symbols) latencies. Note the deviation from linearity in both sets of points, as well as the differences between the two sets of points.

cells than for pyramidal cells, although not significantly (Fig. $5 C$; Table 1). Stellate cells also tended to have lower current thresholds for the first spike and a capacity for sustaining higher maximal discharge rates. The accommodative properties of the two cell types provided the most striking contrast, however. When the intensity of long current pulses was adjusted to give high, but similar, initial spiking frequencies, pyramidal cells failed to sustain these frequencies (Fig. $5 A$ ), while stellate cells usually did (Fig. $5 B$ ). This is illustrated graphically in Fig. $5 D$, which shows that some stellate cells actually increased their firing frequency during the coursc of a long stimulus (filled symbols), whereas all pyramidal cells showed rapid and dramatic accommodation (open symbols).

Morphological identification of cells was accomplished by intracellular labeling with LY or HRP, following physiological classification. The results from the two different dyes were essentially identical. Five HRP-filled neurons recovered from these experiments were of the pyramidal type, and all had electrophysiological behavior similar to that described above. These cells had somata in the cell layer and multiply branching apical dendrites ascending through the molecular layer to the pial surface. There were also shorter basilar dendrites that extended downward into the subcellular zone. The dendritic processes
A
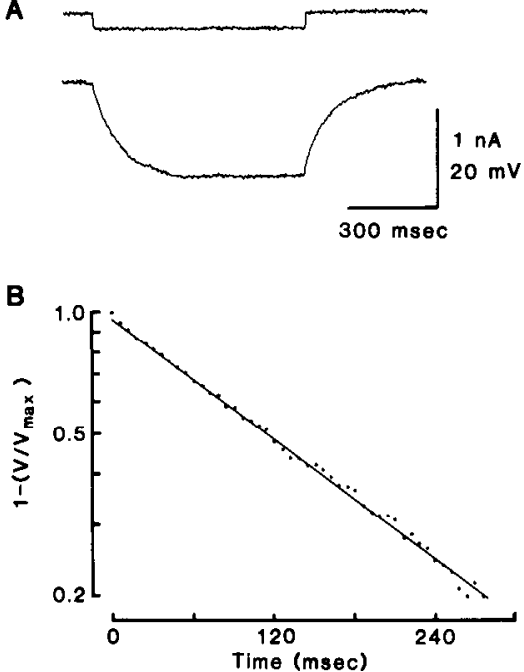

Figure 4. Measurement of membrane time constant $\left(\tau_{\mathrm{m}}\right)$ in a pyramidal cell. $A$, Voltage response (bottom) to an intracellularly applied current pulse (top). $B$, Semilogarithmic plot of voltage transient illustrated in $A$ vs time. $V_{\max }$ is the maximal amplitude of the voltage change, and $V$ is the amplitude of the voltage change at the designated time, with 0 msec marking the onset of the current. A straight line has been fitted to the limiting slope of the resulting points, and the calculated $\tau_{\mathrm{m}}$ is 172 msec.

were densely covered with spines. Figure $6 A$ illustrates a camera lucida drawing of an HRP-filled pyramidal cell from the dorsal cortex. The top panel is viewed from the ependymal surface, as the cell would have appeared in the recording chamber. The bottom panel shows the same pyramidal neuron after embedding and sectioning at $90^{\circ}$ to show its appearance in the coronal plane. Arcades of spine-laden dendrites traverse the molecular layer and also project toward the ependyma. These cells are the principal cortical neurons and match the pyramidal cell morphology that has been described for reptile dorsal cortex (Desan, 1984; Ramon, 1896; Ramon y Cajal, 1911).

Two stellate cells were encountered in the subcellular layers and successfully labeled with HRP. Both had the stellate cell physiology described above, and one of them is illustrated in Figure $6 B$. Dendrites of stellate cells were generally oriented at right angles to the apical dendrites of the pyramidal neurons and parallel to the pial surface. The dendrites were less branched than their pyramidal cell counterparts and bore very few spines. The top panel of Figure $6 B$ shows the cell as viewed through the ependymal surface; the bottom panel shows the same cell reconstructed from serial sections cut at right angles to the ependymal surface.

Intraneuronal injections of LY yielded results that were essentially identical to those of the HRP studies. All nine LYfilled neurons that had relatively slow spikes of variable amplitude and rapid accommodation exhibited pyramidal cell morphology (Fig. 7, $A, B$ ). In contrast, when eight cells with rapid, unitary action potentials and little or no accommodation were recorded and stained, stellate cells were invariably recovered (Fig. 7, C, $D$ ). Unlike some neurons in rat and guinea pig neocortex (Connors et al., 1983; Gutnick and Prince, 1981), neurons of the turtle cortex did not exhibit dye-coupling, i.e., the staining of multiple cells following a single injection.

\section{Golgi-stained neurons}

We compared the morphological features of cortical neurons revealed by the Golgi method with the strict dichotomy of cell types obtained in our physiological experiments. We examined the cerebral cortices from three specimens of adult Pseudemys 
Figure 5. Spike frequency adaptation in pyramidal and stellate cells. $A$, Response of a representative pyramidal cell to a suprathreshold pulse of current. $B$, Response of a representative stellate cell to a similar stimulus. $C$, Plot of action-potential frequency, calculated from the first interspike interval, vs injected current for threc stellate cells (closed symbols) and two pyramidal cells (open sym$b o l s)$. $D$, Spike frequency adaptation in two pyramids (open symbols) and two stellates (closed symbols). Long depolarizing current pulses were applied, as in $A$ and $B$, to generate trains of action potentials. Current intensity was chosen to give similar initial spike frequencies $(80-90 \mathrm{~Hz})$, and frequencies for each subsequent interspike are plotted as a function of time. Note that frequency adapts very quickly in pyramidal cells, whereas adaptation is slight or noncxistent in stellate cells.
A

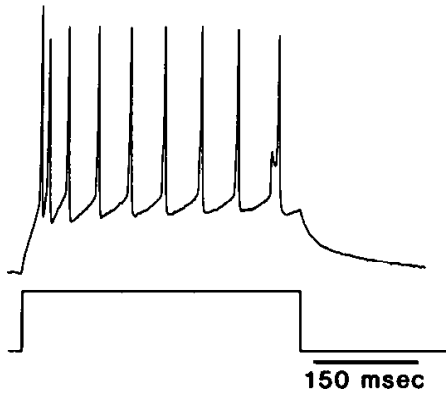

C

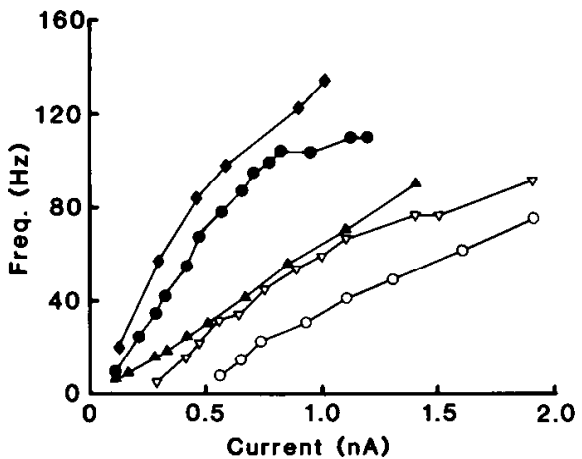

B

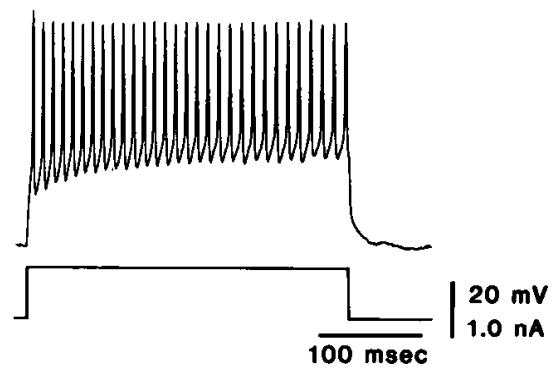

D

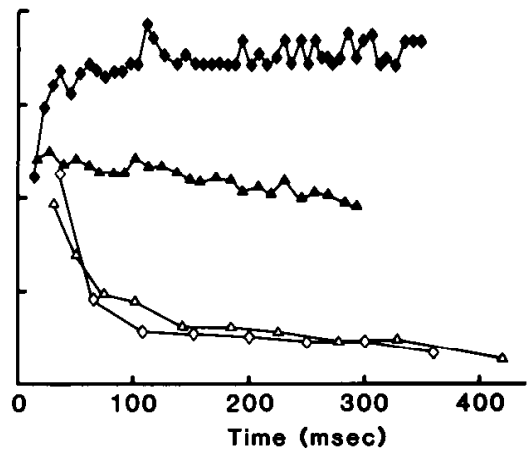

scripta prepared using a rapid Golgi-staining method. Wellimpregnated cells could be easily assigned to the stellate or pyramidal cell categories, with very few exceptions. These exceptions did not appear to constitute unique classes of cells, but instead had some characteristics of both pyramidal and stellate cells.

Camera lucida drawings of several representative pyramidal cells are illustrated in Figure 8. Because our sections were only $50 \mu \mathrm{m}$ thick, and it was difficult to trace processes through adjacent sections, some of the longer dendrites are truncated. Nevertheless, there was remarkable structural homogeneity among the principal cells. The most variable characteristics were the number and length of the basilar dendrites. Basilar elaboration was related to cellular position. The visual area of the turtle cortex has been divided into dorsolateral and dorsomedial divisions, based on architectonics and connectivity (Davydova and Goncharova, 1979; Desan, 1984). The subcellular layer is thicker in the dorsolateral area, where basilar dendrites of pyramidal cells are correspondingly better developed than those of pyramidal cells located more medially.

Cell morphology varied more among stellate cells than among pyramidal cells. Subcellular zone stellate cells bore few, if any, spines, and most had relatively restricted dendritic arbors (Fig. $9, b, c)$. An occasional subcellular stellate cell displayed an unusually long dendrite that projected far into the molecular layer (Fig. 9d). Stellate neurons in the molecular zone commonly had very long aspiny or sparsely spiny dendritic processes, as shown in Figure $9 a$. Photomicrographs of some of the Golgi sections containing pyramidal cells (Fig. 10, $A, B$ ) and stellate cells (Fig. $10, C, D)$ underscore the differences in position and axis of orientation that generally characterize these two cell types. Magnified views illustrate the distinctive dendritic morphologies of pyramidal (Fig. 11, $A, B)$ and stellate $(C, D)$ cell types. The dendrites of stellate cells are generally aspiny and have frequent
Figure 6. Illustration of the two characteristic cell types of turtle cortex as revealed by intracellular HRP injection. $A$, A cell with the characteristic physiological and morphological properties of a pyramidal neuron as viewed in the intact cortex (top panel) and as reconstructed from serial sections cut coronally (below). Note the mutiple ascending apical dendrites laden with spines, and fine recurrent axon collateral branches. $B$, A cell with the physiological and morphological characteristics of a stellate neuron as viewed in the intact cortex (top panel), and as reconstructed in serial sections cut coronally (below). Note the less exuberant dendritic branching pattern, the relative lack of spines, the axis of orientation parallel to the pia, and localization to the subcellular layer. $M L=$ molecular layer, $C L=$ cell layer, $S C L=$ subcellular layer, $E=$ ependymal surface.

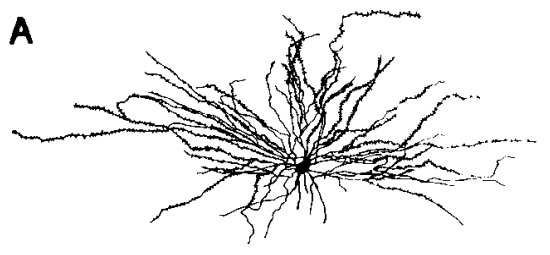

B

$\overline{.100 \mu \mathrm{m}}$

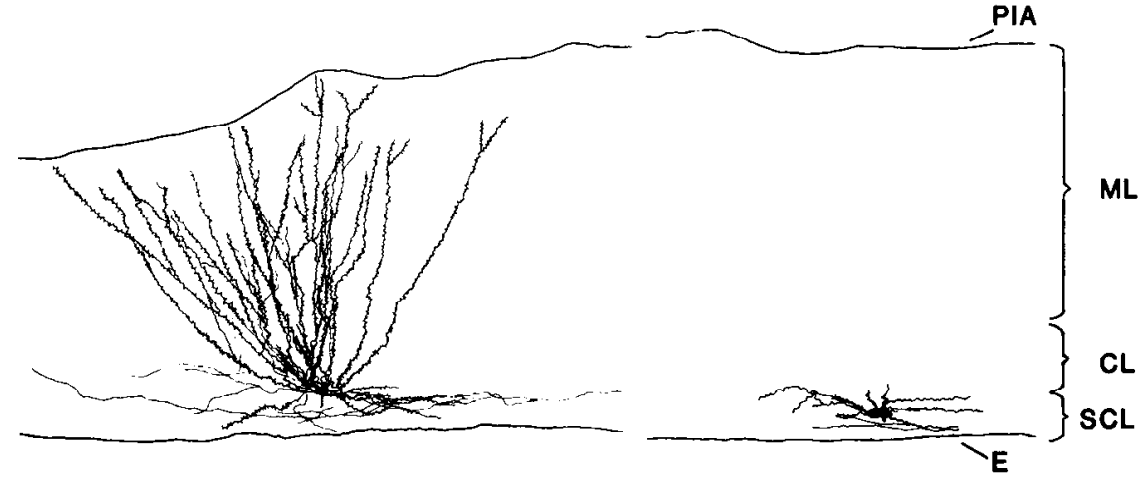



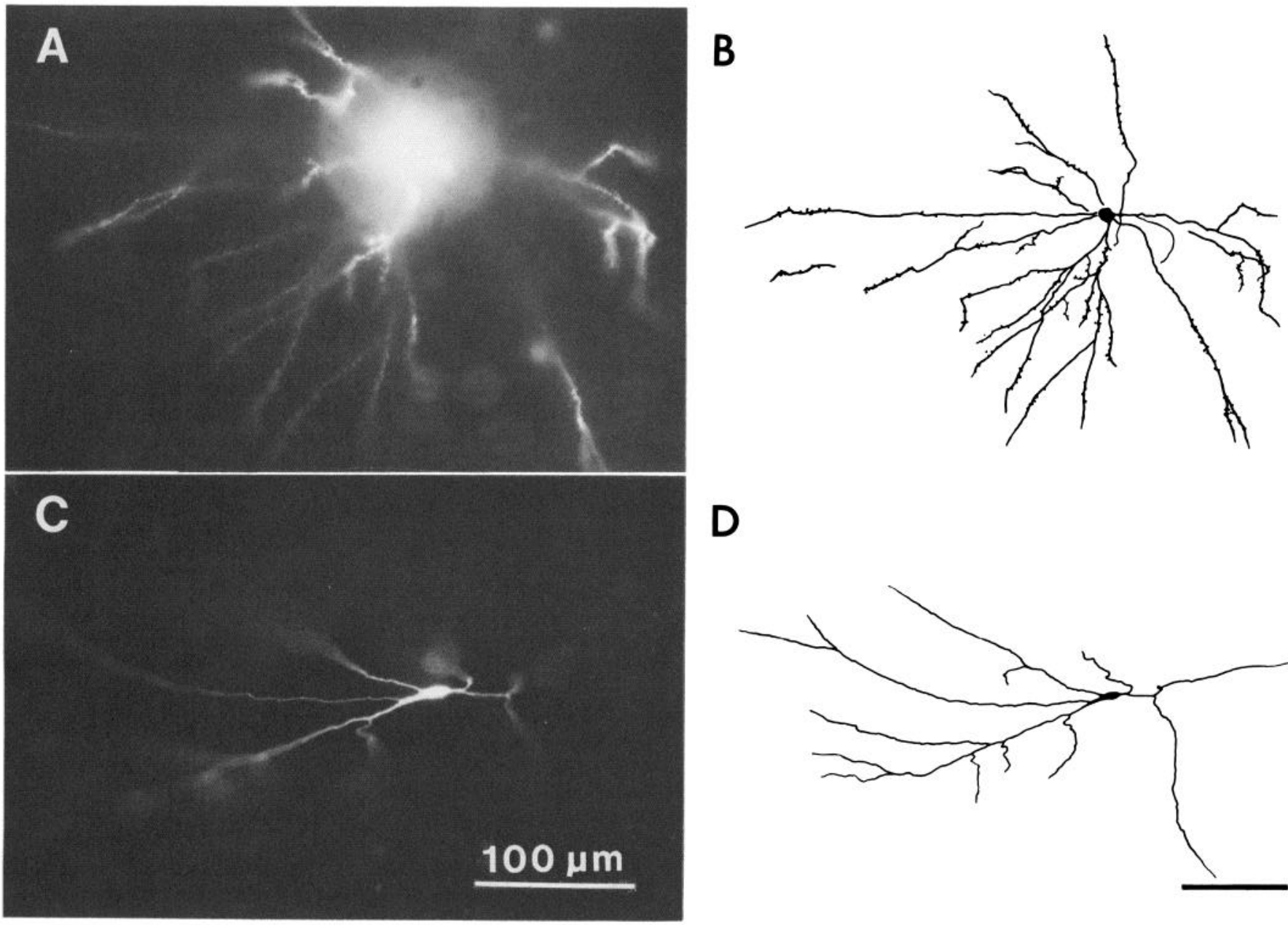

D

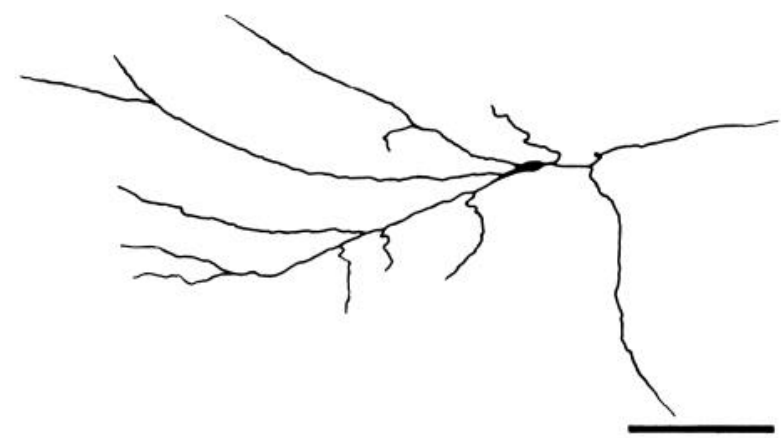

Figure 7. A pyramidal and stellate neuron following intracellular injection of the fluorescent dye, Lucifer Yellow (LY). A, Photograph of a pyramidal cell characterized physiologically prior to intracellular labeling. The cell is viewed from the ependymal surface in whole-mount; the plane of focus is near the distal ends of the apical dendrites. Soma is visible as a bright but unfocused blob. $B$, Reconstruction of the cell shown in $A$. Photomicrographs taken at several planes of focus were projected and traced on paper. $C$, Photograph of a LY-injected cell located in the subcellular layer that had the physiological and morphological properties of a typical stellate cell. In this whole-mount view the dendritic processes travel generally parallel to the pial surface. $D$, Drawing of the cell shown in $C$, as reconstructed from several photomicrographs. It has a relatively simpler dendritic tree with far fewer spines than the pyramidal cell. Calibration bars, $C$ and $D$ are $100 \mu \mathrm{m}$, and apply also to $A$ and $B$.

varicosities along their length. In contrast, pyramidal cell dendrites are covered with spines and are more uniformly tapered.

\section{Characteristics of pyramidal cell action potentials}

The frequency and stability with which pyramidal cells could be impaled allowed us to study their active membrane properties in greater detail. In many cells, it was possible to separate the low-amplitude from the large-amplitude action potentials by carefully grading the intensity of an intracellular current pulse. For example, the neuron illustrated in Figure $12 \mathrm{~A}$ sometimes fired only a small spike to a just-threshold stimulus. At other times, the smaller spike was followed by (or itself triggered) a small spike-large spike complex. Comparison of these evoked waveforms shows that the afterpotentials of the two sizes of spikes were qualitatively different. The small spike alone was followed by a depolarizing potential that decayed within 200 msec (Fig. 12A, middle traces; cf. subthreshold and suprathreshold responses). When a large spike occurred, however, it was always followed by a hyperpolarizing potential (Fig. 12A, top traces) that lasted from 1 to $3 \mathrm{sec}$.

Some pyramidal cells also displayed peculiarities of repetitive firing. For example, when subjected to a long depolarizing current pulse, the cell illustrated in Figure $12 \mathrm{~B}$ initially fired a train of regularly spaced action potentials. After about $4 \mathrm{sec}$, however, it spontaneously converted to an oscillatory firing mode consisting of spike doublets or triplets. In the latter case, spike complexes were separated by slow hyperpolarizations. This rhythmic mode of firing was probably an intrinsic property of the recorded cell, rather than a synaptically imposed property, since the frequency of the rhythms was dependent upon the intensity of the injected current; higher currents yielded increased frequencies, while lower currents either decreased the frequency or failed to generate rhythmic firing.

When extracellular electrical stimuli ( $200 \mu \mathrm{sec}$ duration) were applied to the subcellular layer, or to the ependymal surface, it was sometimes possible to evoke an antidromic action potential in pyramidal cells. As shown in the example of Figure $13 \mathrm{~A}$, such retrogradely conducted spikes were always of small amplitude $(10-20 \mathrm{mV})$ and short duration. Fully invading large-amplitude spikes were never observed. In many cells the initial antidromic spike (Fig. 13A, curved arrow) appeared to trigger a second allor-none component (Fig. 13A, straight arrows). The latency and probability of occurrence of these second spike components were dependent upon the resting-membrane potential; hyperpolarization of 1-2 $\mathrm{mV}$ could block the spike, whereas small depolarizations decreased its latency. As discussed in the fol- 


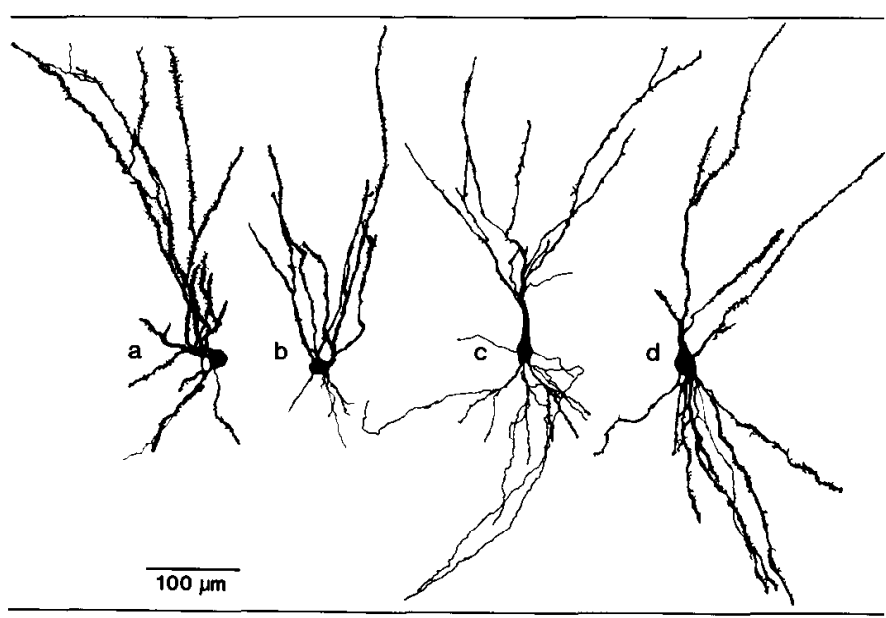

Figure 8. Typical examples of pyramidal neurons of turtle visual cortex as reconstructed from camera lucida drawings of Golgi-stained tissue. Cells $a$ and $b$, with relatively short basilar dendrites, are typical of cells found in the medial area of turtle dorsal cortex. Cells $c$ and $d$, with better developed basilar dendritic trees, are typical of cells found in the lateral dorsal cortex. These neurons are reconstructed from single 50 $\mu \mathrm{m}$ thick sections and therefore are shown with less than their full complement of dendritic branches, as these have been truncated by the margins of the section. The lines at the top and bottom represent the pial and ependymal cortical borders, respectively.

lowing paper (Kriegstein and Connors, 1986), subcellular-layer stimuli also evoked a powerful hyperpolarizing inhibitory synaptic potential, the onset of which could precede the antidromic spike. An antidromic origin for the primary spike is indicated by its narrow range of latencies following single shocks (less than 0.2 msec variation); its smoothly increasing latency when conditioned with a preceding shock at progressively shorter intervals (Fig. 13, B, C; cf. closed circles with control latency); and the sharpness of the refractory period $(6.0 \mathrm{msec}$ in this neuron). The secondary antidromic spike components were completely suppressed by the preceding conditioning shocks.

Antidromic spikes were used in a collision paradigm to test whether the small intracellularly evoked action potentials (Fig. $13 D$, open arrow) were able to invade the axon orthodromically. Short depolarizing current pulses were adjusted to evoke only a small spike; this was paired with a shock to the subcellular zone to evoke an antidromic spike (Fig. 13D, curved arrows). If the small spike evoked at the somatic level did invade the axon, one would predict that the minimal interval between the somatic spike onset and the antidromic stimulus would be the axonal conduction time $(2.3 \mathrm{msec})$ plus the refractory period $(6.0 \mathrm{msec})$, or $8.3 \mathrm{msec}$. However, in the cell of Figure $13 \mathrm{D}$, the minimal interval was $5.5-5.7 \mathrm{msec}$, suggesting that the small, somatically evoked spike did not fully invade the axon in this case. The preceding somatically evoked spike did have other effects on the antidromic spike: at short interstimulus intervals, it inhibited the sccondary component of the antidromic spike (Fig. 13D, third and fourth traces) and slightly increased the antidromic latency (Fig. 13C, open symbols). This experiment proved feasible in only four pyramidal cells. The results of two implied that the somatically evoked small spike did invade the axon orthodromically; the timing of the other two was not consistent with orthodromic invasion, perhaps indicating that the small, intracellularly evoked spike arose in a region of the cell distant from the initial segment.

We investigated the ionic basis of action-potential generation in pyramidal cells. The addition of $10^{-6} \mathrm{M}$ tetrodotoxin (TTX) to the perfusion medium abolished all of the regenerative action potentials recorded through $\mathrm{K}$ acetate-filled microelectrodes,

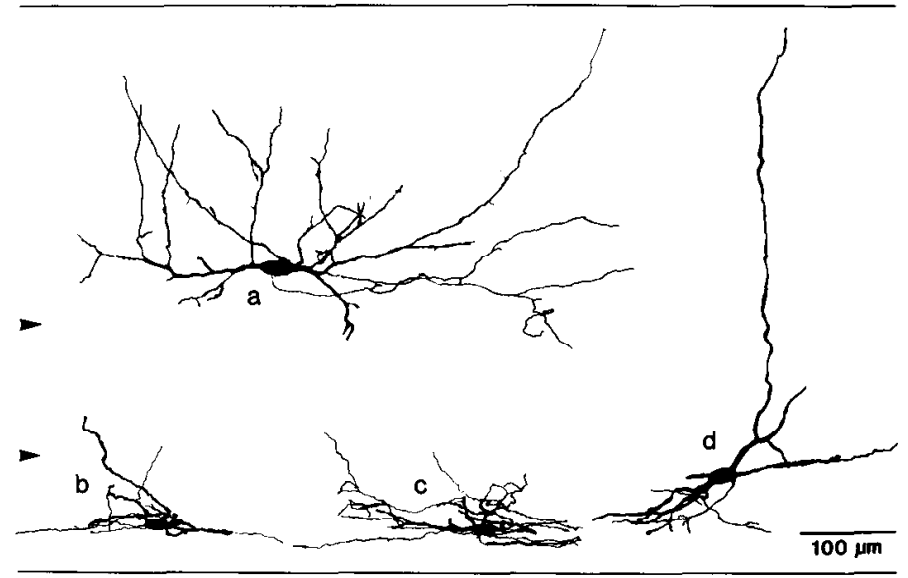

Figure 9. Camera lucida reconstructions of the principal stellate cell morphologies, based on Golgi-stained cortical tissue. The majority of subcellular-layer stellate cells resemble $b$ and $c$. Dendrites of these cells generally travel in the subcellular layer parallel to the pia and bear few, if any, spines. Occasional examples resemble cell $d$ and have one or two processes that ascend into the molecular layer; in other ways, these cells resemble the subcellular-zone neurons depicted in $b$ and $c$. Cell $a$ is a relatively common molecular-layer stellate cell type, fusiform in shape, bearing relatively long aspiny dendrites. Arrowheads indicate the borders of the pyramidal cell layer, and the lines at the top and bottom represent the pial and ependymal borders, respectively.

although some low-amplitude, variable-duration, graded responses persisted (Fig. 14A). This result suggests that sodium is the primary carrier of inward current during both large and small spikes in pyramidal neurons. Since voltage-dependent calcium conductances are found almost universally in neuronal cell bodies, it seemed likely that the residual active responses visible in TTX represented calcium-dependent events. This conclusion was supported by experiments in which manganese, an agent known to suppress calcium conductances (Hagiwara and Byerly, 1981), was focally applied to TTX-treated cells. Manganese greatly reduced or abolished the active events (Fig. 14B). In order to enhance the probability of detecting calcium-dependent electrogenesis, cesium was iontophoretically injected from $1 \mathrm{M}$ cesium chloride-filled microelectrodes by passing small depolarizing current pulses. Intracellular cesium blocks outward potassium currents (Benzanilla and Armstrong, 1972). The effects of cesium injection on pyramidal cell spikes are shown in Figure $15, A, B$. As cesium was injected, large-amplitude spikes progressively broadened and developed a prominent shoulder on the falling phase; however, small-amplitude spikes were not obviously affected. Although the maximum rates of rise were not altered, cesium slowed the rates of repolarization. Coincident with these changes, the afterhyperpolarization reversed polarity and became a large, long, depolarizing afterpotential. Applications of TTX to cesium-injected cells yielded large-amplitude, broad TTX-resistant spikes with very slow rates of rise and prominent depolarizing afterpotentials (Fig. 15, C, D). Addition of manganese to cesium- and TTX-treated cells abolished all action potentials. These results are consistent with the presence of voltage-dependent calcium channels in the somadendritic membrane of cortical pyramidal neurons.

\section{Discussion}

The primary conclusion of this investigation is that the two structurally defined types of neurons in the dorsal cortex, pyramidal cells and stellate cells, have distinctly different physiological properties. Moreover, each cell type in turtle cortex displays many similarities to a corresponding cell type in the neocortex of mammals. 


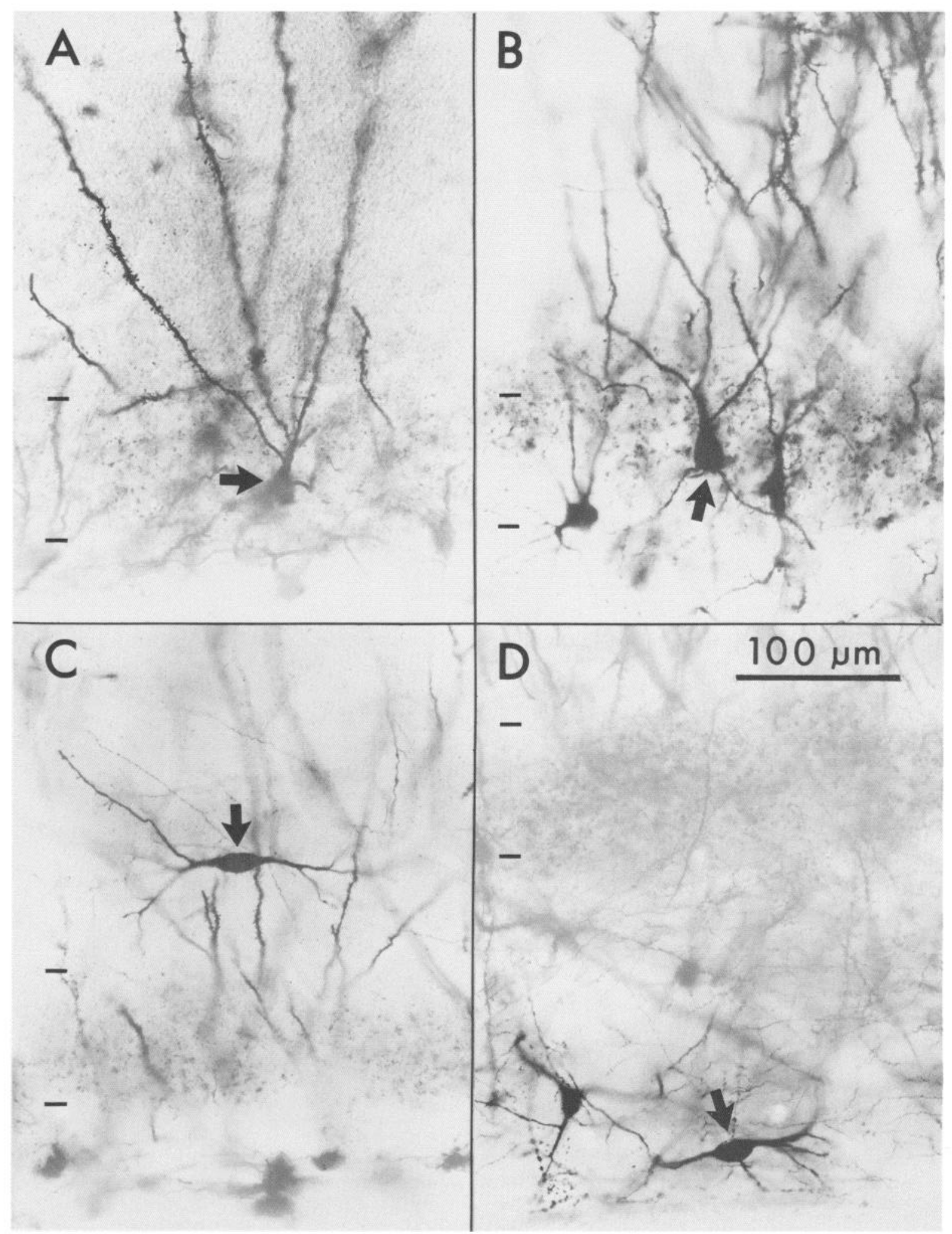

Figure 10. Photographs of Golgi-stained material showing characteristic cellular morphologies. $A$ and $B$, Pyramidal cell bodies (arrows) are located within the cell layer (between the tick marks), an area that often appears slightly stippled in Golgi-stained material. Spiny dendrites can be seen ascending upward to the molecular layer, and basilar dendrites descending into the subcellular zone. $C$ and $D$, Typical stellate cells (arrows) located in the molecular layer $(C)$ and the subcellular layer $(D)$. Each has a fusiform soma and aspiny dendrites. Calibration in $D$ applies to all panels.

\section{Dichotomy of neuronal types in dorsal cortex}

Morphological studies using Golgi methods (Balaban, 1978; Davydova and Goncharova, 1979; Desan, 1984; Northcutt,
1970; Ramon, 1896; Ramon y Cajal, 1911; this study), electron microscopy (Ebner and Colonnier, 1975) and intracellular staining with HRP and LY (this study) indicate that virtually all neurons of the dorsal cortex fall into two general categories. 

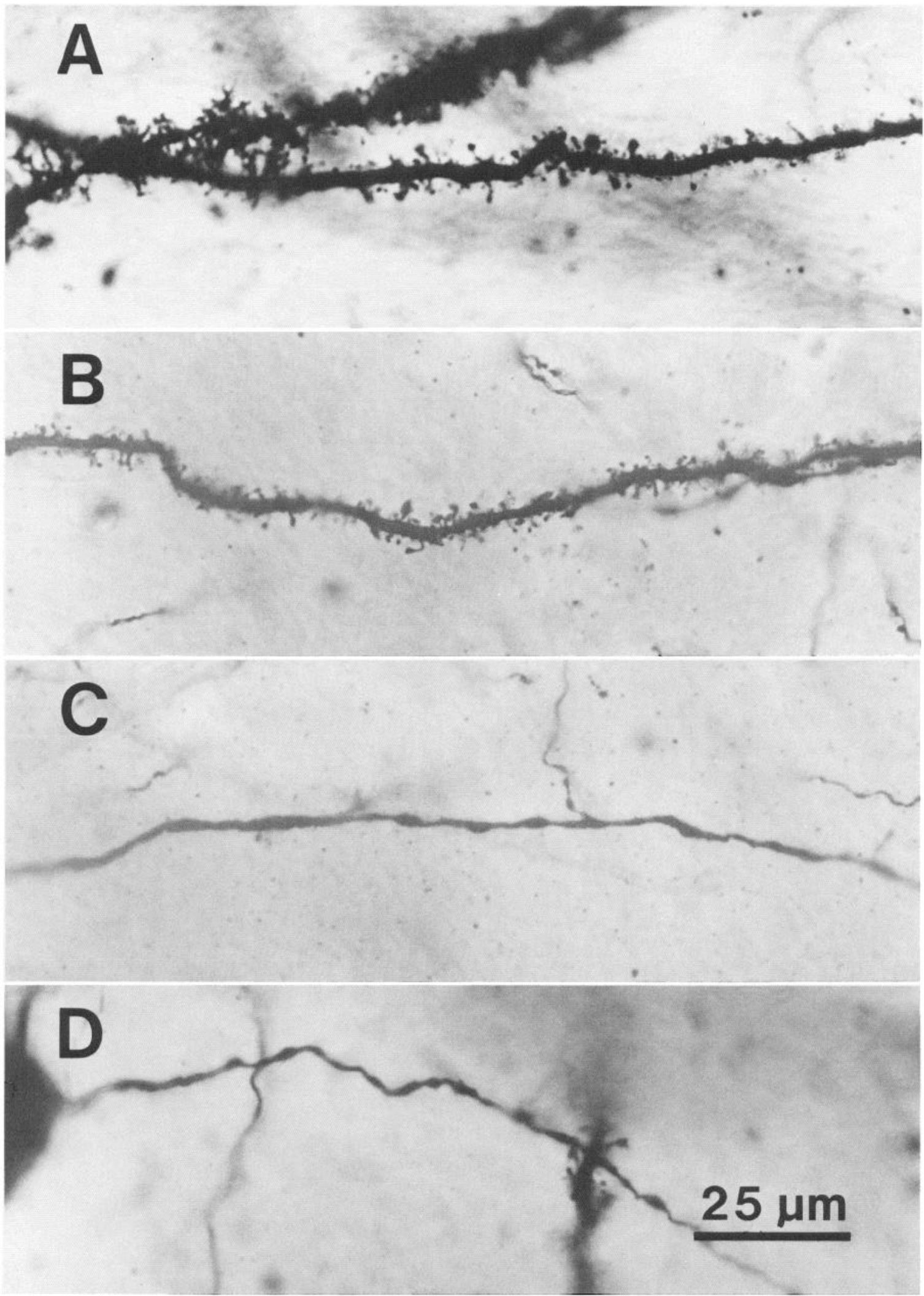

Figure 11. Dendritic morphology of cortical neurons in Golgi-stained tissue. $A$ and $B$ are secondary dendritic branches of pyramidal neurons. Each is covered with pedunculated spines. Thick, obliquely oriented process in $A$ is from an ependymal cell. $C$ and $D$ are secondary dendritic branches of stellate interneurons. They bear few, if any, spines and have numerous varicosities along their length. Calibration in $D$ applies to all panels. 

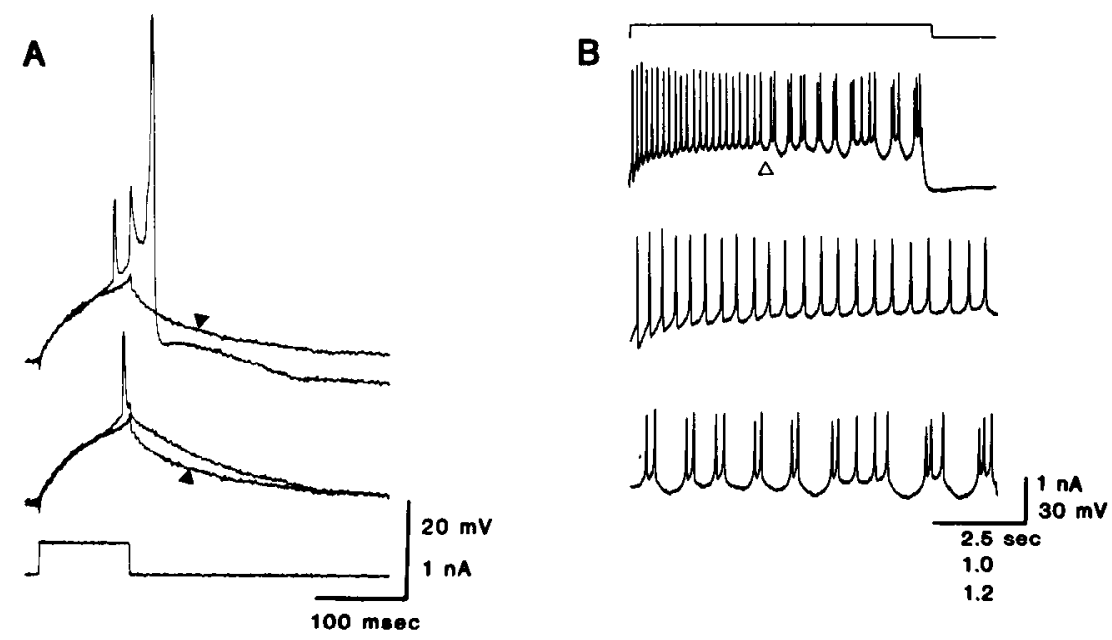

Figure 12. Action-potential characteristics of pyramidal neurons. A, Stimulation with a short intrasomatic current pulse (bottom trace) shows that small amplitude spikes can be generated in isolation. A $100 \mathrm{msec}$ current pulse was adjusted to be near threshold. The top trace shows a complex of two small spikes followed by a full-sized spike. The response to the next stimulus (marked by triangle) was subthreshold, and is superimposed on the first. Note the large post-spike undershoot (cf. subthreshold to suprathreshold responses). The subthreshold response is reproduced in the second set of traces (triangle), and the response to a third stimulus presentation is superimposed. In this case, only a single small spike was generated, and it was followed by a brief depolarizing afterpotential. $B$, Oscillatory mode of repetitive firing. A different pyramidal cell from $A$ was subjected to a long suprathreshold current pulse (top trace). In response, it initially generated a train of tonically firing action potentials followed, after about $4 \mathrm{sec}$, by a sudden shift to phasic bursts of two and then three spikes (middle trace). The response is shown at higher sweep speed in the lower traces, which are derived from the area to the left and right of the triangle above. Note differences in time calibrations for the three voltage traces.

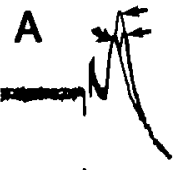

$\mathbf{A}$

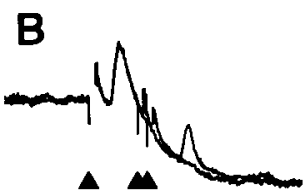

C

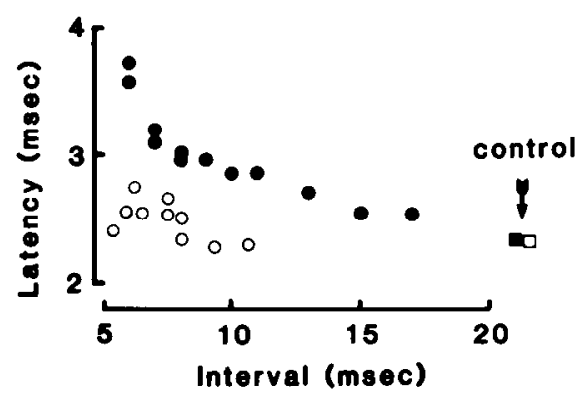

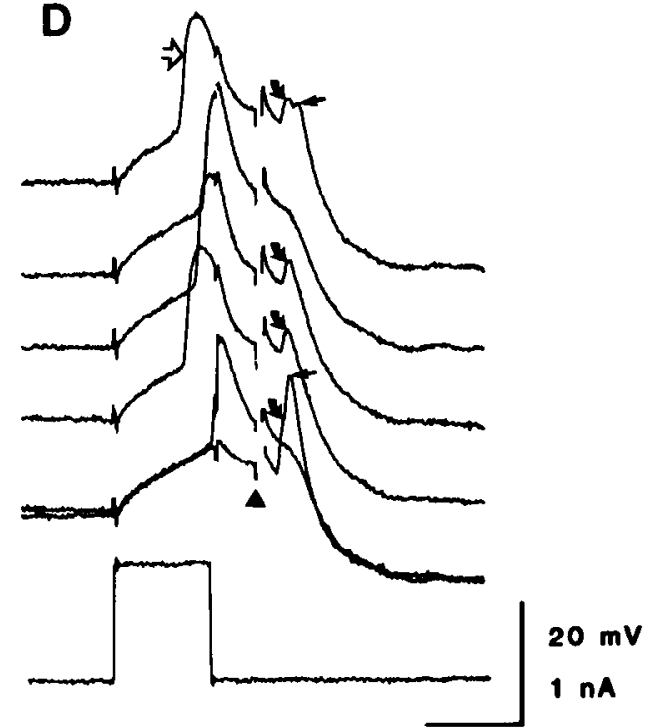

$10 \mathrm{msec}$

Figure 13. Antidromic action potentials of a pyramidal cell. A, Response to ependymal shocks (triangle). Antidromic spike (curved arrow) was elicited at a sharp current threshold, and maintained a relatively fixed latency. Secondary spikes (straight arrows) sometimes appeared at a longer and very variable latency, shown here in three superimposed sweeps. $B$, Paired shocks to the ependymal layer (three superimposed sweeps). The initial shock evoked an antidromic spike and an inhibitory postsynaptic potential; the latency of the second shock was varied and at 6.0 msec evoked a spike, whereas at $5.1 \mathrm{msec}$ it did not. Repeated trials at varying intervals indicated an absolute refractory period of slightly less than 6.0 msec. $C$. Latency between ependymal layer shock and onset of the antidromic spike. Closed symbols are derived from the experiment shown in $B$. Control latency (closed square) was measured from a series of single shocks and varied by less than $0.2 \mathrm{msec}$ in 10 trials. When a preceding shock was applied at decreasing intervals, latencies progressively lengthened (closed circles) before spike failure at interstimulus intervals of less than $6.0 \mathrm{msec}$. Open symbols are derived from the experiment illustrated in $D$. In this case, the plotted interval is the time between the onset of the somatically evoked spike (open arrow in $D$ ) and the shock to the ependymal layer (triangle in $D$ ). Latency is measured from the shock to the antidromic spike onset. Control latency (open square) was measured from trials in which the preceding intrasomatic stimulus was subthreshold. $D$. Attempted collision experiment between a small action potential generated by an intracellular current pulse (open arrow) and a subsequent antidromic spike (curved arrows). Trial-to-trial variation in the onset time of the preceding action potential (top to bottom) allowed estimation of the minimal interval between the first spike and the subsequent stimuli that evoked antidromic spikes that successfully invaded the recording site. Thus, failure occurred in the second and fifth sweeps, but not in the first, third and fourth. The fifth trace also shows a control trial in which the preceding current pulse was subthreshold. Note that secondary antidromic spikes (straight arrows) were delayed or blocked by preceding spikes at short intervals. Calibrations in $D$ also apply to $A$ and $B$. 
A

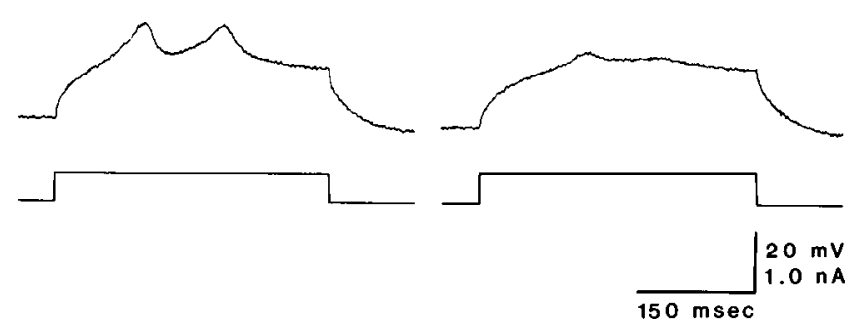

Figure 14. $A$, The voltage response of a pyramidal cell in the presence of $10^{-6} \mathrm{M}$ TTX, consisting of small, slow, graded depolarizations. $B$, Focal application of $20 \mathrm{~mm}$ manganese, a calcium current antagonist, to the cell depicted in $A$ markedly attenuated slow depolarizations.

Pyramidal cells have spine-laden apical and basal dendrites and somata in the cell layer, whereas stellate cells have relatively smooth dendrites with somata scattered through all layers. Many authors (Balaban, 1978; Desan, 1984; Ramon, 1896), have commented upon the structural variability of neurons within these classes. For example, pyramidal cells may have somata displaced to the molecular or subcellular layers; their soma shape may vary dramatically and the density of their basilar dendrites ranges from nonexistent to equal to the apical arborization. Stellate cells display even wider variation in the size and pattern of their dendritic arbors, the shapes of their somata, and their orientations. Many of these differences were apparent among our intracellularly stained neurons. Nevertheless, the two morphologically defined cell types correlated absolutely with the two physiologically defined cell types; the structural variations within each type did not obviously correlate with functional variations, although more extensive investigation may demonstrate such correlates. Thus, pyramidal cells are characterized by both large- and small-amplitude action potentials, or obvious breaks in the rising limb of their spikes, and a marked adaptation of spike frequency during prolonged depolarization. Stellate cells have more rapidly rising and falling action potentials of uniform large size, prominent post-spike undershoots, and little or no adaptation. The two neuron types also have significantly different membrane time constants (Table 1). If we make the reasonable assumption that the specific capacitance of their membranes is the same (Cole, 1968), then it is likely that the pyramidal cells have a specific membranc resistance ncarly threc times higher than that of the stellate cells.

In a companion study (Kriegstein and Connors, 1986), we investigate the functional properties of local connections within the turtle dorsal cortex. The results demonstrate that pyramidal and stellate neurons are also differentiable by their synaptic responses to local stimuli; pyramidal cells are profoundly inhibited while stellate cells are strongly excited. We propose that the combination of action-potential characteristics and synaptic responses allows unambiguous identification of an intracellularly recorded neuron as pyramidal or stellate.

We are not aware of any previous descriptions of the characteristics of turtle cortical neurons recorded intracellularly. However, there have been several studies in which single neurons were recorded extracellularly (Bass et al., 1983; Belekhova, 1979; Gusel'nikov et al., 1974; Karamian et al., 1966). Although these authors did not report the characteristics of the spikes they observed, in principle it might be possible to identify the cell type by the shape and speed of its action potential recorded extracellularly, as well as by its laminar position (cf. Mountcastle et al., 1969).

We can only speculate about the significance of the differences in membrane properties between the two cortical cell types.
A
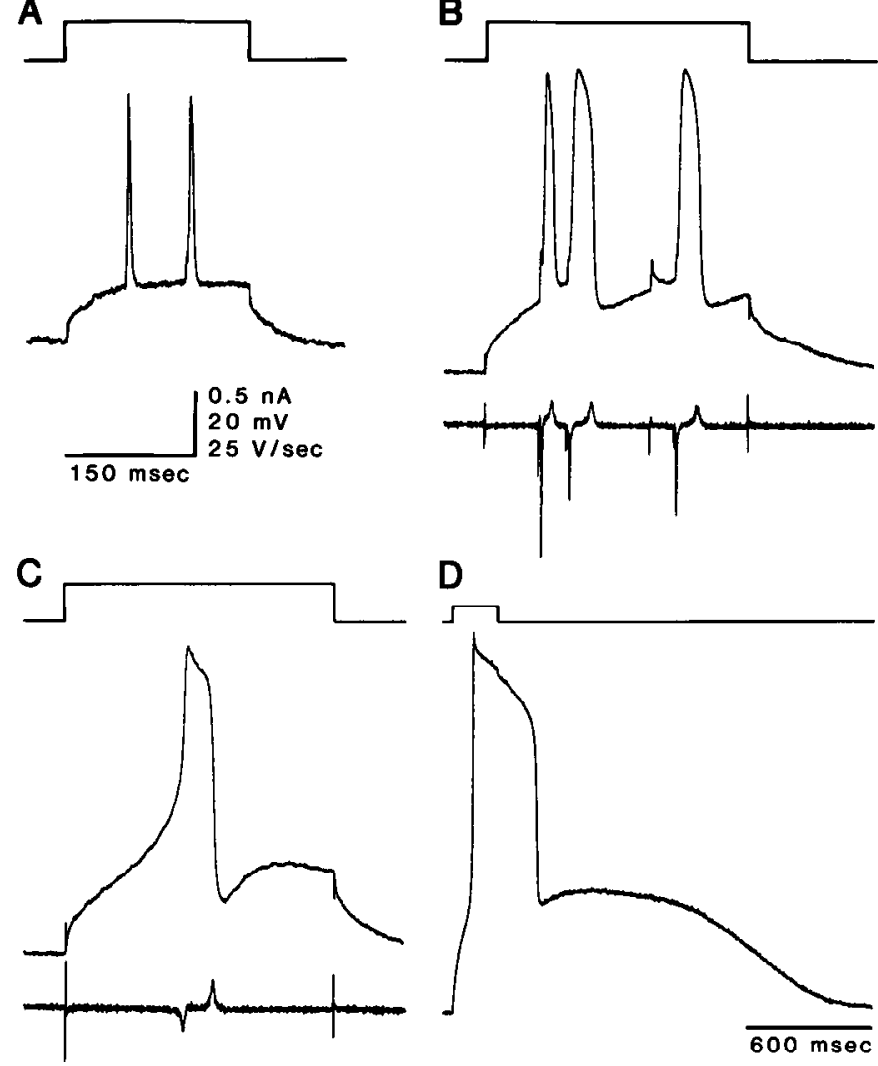

Figure 15. Initiation of nonsodium-dependent action potentials in pyramidal cells. $A$, Voltage response of a pyramidal cell to a depolarizing current pulse immediately after impalement with a cesium-filled microelectrode. $B$, Following $15 \mathrm{~min}$ of intracellular cesium injection, the large-amplitude action potentials have greatly increased in duration. Note that a small spike was evoked, but has a relatively normal duration. The differentiated tracing, below, reveals the relatively rapid rising phase of the action potentials. Same cell as in $A$. $C$, Addition of $10^{-6} \mathrm{M}$ TTX to the bathing medium in $B$. The differentiated trace below shows that TTX eliminated the rapid rising phase of the action potential. Same cell as $A$ and $B . D$, A different cell, also injected with cesium and bathed in TTX. A short current pulse evoked a large, broad action potential that was followed by a prominent depolarizing afterpotential. Calibrations in $A$ apply also to $B-D$, except for the time scale in $D$.

Their respective responses to prolonged, constant stimuli imply that pyramidal cells are most sensitive to transient or phasic excitation, whereas stellate cells faithfully transform a tonic excitation into a sustained output. These characteristics correlate well with the synaptic processes (Kriegstein and Connors, 1986) and physiological responses (Belekhova, 1979) of turtle cortical neurons, in which excitation is generally phasic while local inhibition is relatively prolonged.

\section{Action potentials of pyramidal cells}

The most unusual characteristic of pyramidal cells in the dorsal cortex is their propensity to generate action potentials of more than one amplitude. There are several relevant observations worth listing: (1) The majority of cells displayed spikes of two discrete amplitudes; their sizes across cells were quite similar, about 76 and $34 \mathrm{mV}$. (2) The smaller-amplitude spike almost always had a lower threshold than the larger one. (3) Small spikes yielded brief depolarizing afterpotentials, whereas large spikes evoked prominent long-lasting hyperpolarizing afterpotentials. (4) Antidromically evoked action potentials were usually even smaller than the intracellularly evoked small-amplitude spike, 
and were sometimes associated with a second, small, all-or-none component. (5) In at least some cases, the small, somatically cvoked spikes propagated orthodromically. (6) Activation of orthodromic pathways to distal dendrites could also evoke smallamplitude action potentials; because of concurrent IPSPs, these spikes arose from a voltage more negative than the resting potential, as viewed from the recording site (see Fig. 2 of Kriegstein and Connors, 1986). (7) All regenerative action potentials were blocked by TTX under normal conditions.

The absence of fluorescent dye-coupling between pyramidal cells makes it unlikely that small-amplitude spikes arise from electrical continuity between cells. One parsimonious explanation for the complex data is that the somadendritic membrane of turtle pyramidal cells has multiple sites for sodium-dependent spike generation. The most compelling evidence for this is the ability of distally generated EPSPs to elicit regenerative spikes recordable in the soma, even when the baseline membrane potential of the soma is hyperpolarized because of synaptic inhibition. Presumed excitatory synapses are seen almost exclusively on dendrites, whereas presumed inhibitory synapses contact both dendrites and somata (Ebner and Colonnier, 1975, 1978). The axon hillock usually arises from the soma (Ramon, 1896), although in some cells it may be located on a proximal dendrite (Desan, 1984; P. H. Desan, personal communication). Thus, distal apical dendritic excitation elicited by a single electrical stimulus is unlikely to trigger spikes directly from the axon initial segment or the perisomatic region. Dendrites themselves are probably the site of electrogenesis under these circumstances. At least some of the small action potentials evoked by intrasomatic current injection may also be of dendritic origin. While initiation in the axon cannot be ruled out, their attenuated size and protracted rate of repolarization suggests a site of origin far from the soma. Conversely, large-amplitude spikes, with their dramatic afterpotentials, are likely to arise near the recording site in the soma-proximal dendrite region. The collision experiments, which used small spikes as conditioning stimuli, suggest the intriguing possibility that excitation of the axon may not always require full-spike initiation in the soma.

The relative distribution of ion channel densities cannot be inferred from the available data. At a minimum, it appears that voltage-sensitive sodium channels must exist in the axonal, perisomatic, and distal dendritic membranes. Focal areas of relatively high channel density may occur in distal dendrites, as hypothesized for hippocampal pyramids of mammals (cf. Spencer and Kandel, 1961; Traub and Llinas, 1979). Mitral cells of the turtle olfactory bulb may also generate action potentials in their distal dendrites (Mori et al., 1982). Interestingly, Ebner and Colonnier (1975) observed unusually large, organelle-filled spines on the distal dendrites of turtle pyramidal cells, and speculated that they might be sites of active electrical processes. However, even a neuron with a uniformly excitable membrane may display sites of impulse initiation far from the soma, under appropriate geometrical conditions (Moore et al., 1983; Ramon et al., 1976). The small size and multiple all-or-none components of the somatically recorded antidromic spikes may also be a simple consequence of geometry; in this case the smalldiameter axon may not generate enough action current to overcome the abrupt increase in capacitive load at the soma (compare our Fig. 13, $A, D$ to Figs. 3 and 4 of Ramon et al. 1976). Concurrent synaptic conductances may also contribute to the antidromic impedance mismatch. The failure of action potentials to fully invade the pyramidal cell soma is reminiscent of the frog motoneuron, in which fully invading antidromic spikes are the exception (Magherini et al., 1976).

Elucidation of the mechanisms and significance of multiple spike heights and initiation sites awaits the results of further experimentation. However this characteristic clearly distinguishes turtle pyramidal cells from turtle stellate cells.

\section{Comparison of turtle and mammalian cortical neurons}

Although it would be very interesting to compare the cellular physiology of telencephalic cortical neurons across a large number of vertebrate species, there are currently data for only a few mammals and for one species of reptile. Morphologically, the turtle pyramidal neuron is very similar to the hippocampal pyramidal cell (Ramon y Cajal, 1911). The pyramidal cells of dorsal cortex and neocortex also share many characteristics. Both types have spine-laden apical and basilar dendritic processes, apical dendrites that ascend to more superficial cortical layers, and axons that constitute the principal cortical output. The turtle pyramidal neuron usually has multiple apical dendrites rather than the prominent single apical dendrite that characterizes most neocortical pyramidal neurons. However, the distribution of spines along the apical dendrites is very similar. Spine density varies as a function of distance from the soma in pyramidal neurons of both turtle and mammalian somatosensory cortex (Jones and Powell, 1969). In addition, the same variety of spine morphologies has been described in turtle neurons and in mammalian somatosensory cortex.

The electrophysiological properties of turtle pyramidal neurons resemble mammalian pyramidal cells in several ways. For example, while the action potential of the turtle pyramidal cell is relatively prolonged (at $22^{\circ} \mathrm{C}$ ), we have inferred an ionic dependence on voltage-sensitive sodium, calcium, and potassium channels that is grossly similar to pyramidal neurons of mammalian neocortex and hippocampus (Crill and Schwindt, 1983). The prominence of multiple spike sizes in adult turtle pyramidal cells is reminiscent of mammalian hippocampal cells (Spencer and Kandel, 1961), but differentiates turtle cells from their mature neocortical counterparts, which generate only large somatic spikes in almost all reports. However, Purpura et al. (1965) described multiple spike amplitudes in some neurons of the immature kitten neocortex, and speculated that the small action potentials might arise from dendritic electrogenesis. Interestingly, $\tau_{m}$ for turtle pyramidal cells is several times longer than that for mammalian pyramidal cells in vitro (cf. Connors et al., 1982; McCormick et al., 1985; Stafstrom et al., 1984). The membranes of reptilian cells may therefore have a higher specific resistivity, but some or all of this difference may be due to a strong dependence of membrane resistivity on temperature (cf. Scholfield, 1978).

The structure of the aspiny stellate neurons of turtle cortex closely resembles that of the aspiny stellate neurons of mammalian neocortex and hippocampus. Ultrastructurally, neocortical aspiny stellate cells have greater densities of cytoplasmic organelles and higher frequencies of somatic and proximal dendritic synapses than neocortical pyramidal cells (Colonnier, 1968; Feldman and Peters, 1978; Peters, 1971; White, 1978). The neocortical stellate cell has multipolar dendritic processes and an axon that makes symmetrical contacts onto pyramidal cells (LeVay, 1973; Peters and Fairen, 1978). These contacts are presumed to be inhibitory (Atwood et al., 1972; Uchizono, 1964). These same features have been described for stellate cells in turtle general cortex (Ebner and Colonnier, 1978; Smith et al., 1980). In addition, there is immunohistochemical evidence that aspiny stellate cells in neocortex and hippocampus use the inhibitory substance, $\gamma$-aminobutyric acid (GABA), as their transmitter (Ribak, 1978; Ribak et al., 1978). Immunohistochemical studies have also shown that turtle stellatc cells stain positively for GABAergic markers (Blanton et al., 1985). In the following paper (Kriegstein and Connors, 1986), we provide physiological data in support of the GABAergic inhibitory role of the aspiny stellate cell in turtle cortex.

The relative simplicity of turtle dorsal cortex is underscored by the apparent absence of several cell types present in mammalian neocortex. Most notably, these include the spiny stellate 
cells prevalent in layer IV (Lund, 1984) and the sparsely spiny non-GABAergic bipolar cells, subsets of which contain a variety of neuroactive peptides (Emson and Hunt, 1984).

There have been few studies linking the membrane properties of nonpyramidal neocortical neurons with their corresponding cellular morphology. In a recent investigation (McCormick et al., 1985), the physiological properties of guinea pig neocortical neurons were correlated with somadendritic structure by using LY injections. The results strongly suggested that pyramidal cells were distinguishable from probable GABAergic stellate cells by physiological criteria alone. Thus, pyramidal cells had relatively slowly falling spikes, prominent spike-frequency adaptation, and responded to local stimuli with brief excitation, followed by prolonged inhibition. Stellate cells had very fast spikes, large post-spike undershoots, little or no adaptation, and responded with prolonged synaptic excitation. Similar studies have been conducted for stellate neurons in mammalian hippocampus in vitro (Schwartzkroin and Mathers, 1978). These cells are greatly outnumbered by the principal pyramidal cells, their dendrites are aspiny and often contain varicosities, and they have locally ramifying axons. Physiologically, the dichotomy between pyramidal and stellate cell types in the hippocampus closely resembles that described for the neocortex.

Thus, pyramidal cells in turtle dorsal cortex, mammalian hippocampus, and neocortex are very similar when compared in several general categories: somadendritic morphology, actionpotential properties, and length of axon. By these same criteria, stellate cells from the turtle cortex likewise resemble many of the stellate cells in mammalian hippocampus and neocortex. The stellate cells in question also seem to share the biochemical machinery associated with the transmitter GABA. These observations suggest the possibility that the two neuron types are homologous in reptiles and mammals, and that the characteristics of these primary cortical elements have been highly conserved. A more extensive comparison of cortical neurons across species may help to test this hypothesis.

\section{References}

Atwood, H. L., F. Lang, and W. Morin (1972) Synaptic vesicles: Selective depletion in excitatory and inhibitory axons. Science 126: 1353-1355.

Balaban, C. D. (1978) Structure of the pallial thickening in turtles (Pseudemys scripta elegans). Anat. Rec. 190: 330-331.

Bass, A. H., M. L. Andry, and R. G. Northcutt (1983) Visual activity in the telencephalon of the painted turtle, Chrysemys picta. Brain Res. 263: 201-210.

Belekhova, M. G. (1979) Neurophysiology of the forebrain. In Biology of the Reptilia, Vol. 10, Neurology B, R. G. Northcutt and P. Ulinski, eds., pp. 287-359, Academic, London.

Belkin, D. A. (1963) Anoxia: Tolerance in reptiles. Science 139:492493.

Benzanilla, F., and C. M. Armstrong (1972) Negative conductance carried by entry of sodium and cesium into potassium channels of squid axons. J. Gen. Physiol. 60: 588-608.

Blanton, M., J. Shen, and A. R. Kriegstein (1985) Stellate neurons in the turtle dorsal cortex contain $\gamma$-aminobutyric acid and its synthetic enzyme. Soc. Neurosci. Abstr. 11: 802.

Cole, K. S. (1968) Membranes, Ions and Impulses, University of California Press, Berkeley.

Colonnier, M. (1968) Synaptic patterns on different cell types in the laminae of the cat visual cortex: An electron microscopic study. Brain Res. 9: 268-287.

Connors, B. W., and B. R. Ransom (1982) Electrophysiological studies of ependymal cells of the turtle cortex. Soc. Neurosci. Abstr. 8: 237.

Connors, B. W., L. S. Benardo, and D. A. Prince (1983) Coupling between neurons of the developing rat neacortex. J. Neurosci. 3: 773782.

Connors, B. W., M. J. Gutnick, and D. A. Prince (1982) Electrophysiological properties of neocortical neurons in vitro. J. Neurophysiol. 48: 1302-1320.
Connors, B. W., A. R. Kriegstein, and B. R. Ransom (1983) Cellular physiology of the turtle cortex. Soc. Neurosci. Abstr. 9: 679.

Crill, W. E., and P. C. Schwindt (1983) Active currents in mammalian central neurons. Trends Neurosci. 6: 236-240.

Davydova, T. V., and N. V. Goncharova (1979) Comparative charactcrization of the basic forcbrain cortical zones in Emys orbicularis (Linnaeus) and Testudo horsfieldi (Gray). J. Hirnforsch. 20: 245-262.

Desan, P. H. (1984) The organization of the cerebral cortex of the pond turtle, Pseudemys scripta elegans. Ph.D. dissertation, Harvard University, Cambridge, MA.

Diamond, I. T., and W. C. Hall (1969) Evolution of neocortex. Science 164: 251-262.

Dowling, J. E. (1970) Organization of vertebrate retinas. Invest. Ophthalmol. 9: 655-680.

Ebner, F. F., and M. Colonnier (1975) Synaptic patterns in the visual cortex of turtle: An electron microscopic study. J. Comp. Neurol. 160: $51-80$.

Ebner, F. F., and M. Colonnier (1978) Quantitative studies of synapses in turtle visual cortex. J. Comp. Neurol. 179: 263-276.

Emson, P. C., and S. P. Hunt (1984) Peptide-containing neurons of the cerebral cortex. In Cerebral Cortex, Vol. 2. Functional Properties of Cortical Cells, E. G. Jones and A. Peters, eds., pp. 145-172, Plenum, New York.

Engle, E., V. Barcilon, and R. S. Eisenberg (1972) The interpretation of current-voltage relations recorded from a spherical cell with a single microelectrode. Biophys. J. 12: 384-403.

Feldman, M. L., and A. Peters (1978) The forms of non-pyramidal neurons in rat visual cortex. J. Comp. Neurol. 179: 761-794.

Gusel'nikov, V. I., A. S. Pivovarov, and L. E. Tsitolovsky (1974) Synaptic processes in the neurons of the forebrain general cortex of the turtle to visual stimulation. Zh. Vyssh. Nerv. Deyat. Pavlova 24: 800-810.

Gutnick, M. J., and D. A. Prince (1981) Dye-coupling and possible electrotonic coupling in the guinea pig neocortical slice. Science 211: 67-70.

Hagiwara, S., and L. Byerly (1981) Calcium channel. Ann. Rev. Neurosci. 4: 69-125.

Hall, W. C., and F. F. Ebner (1970) Thalamotelencephalic projections in the turtle (Pseudemys scripta). J. Comp. Neurol. 140: 101-122.

Hall, J. A., R. E. Foster, F. F. Ebner, and W. C. Hall (1977) Visual cortex in a reptile, the turtle (Pseudemys scripta and Chrysemys picta). Brain Res. 130: 197-216.

Harless, M., and H. Morlock (1979) Turtles: Perspectives and Research, Wiley, New York.

Hohmann, C. F., P. T. Carroll, and F. F. Fbner (1983) Acetylcholine levels and choline acetyltransferase activity in turtle cortex. Brain Res. 258: 120-122.

Jones, E. G., and A. Peters (eds.) (1984) Cerebral Cortex, Vol. 2. Functional Properties of Cortical Cells, Plenum, New York.

Jones, E. G., and T. P. S. Powell (1969) Morphological variations in the dendritic spines of the neocortex. J. Cell Sci. 5: 509-529.

Karamian, A. I., N. P. Vesselkin, M. G. Belekhova, and T. M. Zagorulko (1966) Electrophysiological characteristics of tectal and thalamo-cortical divisions of the visual system in lower vertebrates. J. Comp. Neurol. 127: 559-576.

Kitai, S. T., and G. A. Bishop (1981) Horseradish peroxidase. Intracellular staining of neurons. In Neuroanatomic Tract-Tracing Methods, L. Heimer and M. J. Robards, eds., pp. 263-277, Plenum, New York.

Kriegstein, A. R., and B. W. Connors (1984) Synaptic interactions and neurotransmitter responses of turtle visual cortex. Soc. Neurosci. Abstr. 10:659.

Kriegstein, A. R., and B. W. Connors (1986) Cellular physiology of the turtle visual cortex: Synaptic properties and intrinsic circuitry. J. Neurosci. 6: 178-191.

LeVay, S. (1973) Synaptic patterns in the visual cortex of the cat and monkey: Electron microscopy of Golgi preparations. J. Comp. Neurol. 150: 53-86.

Llinas, R. (ed.) (1969) Neurophysiology of Cerebellar Evolution and Development, American Medical Association, Chicago.

Lund, J. S. (1984) Spiny stellate cells. In Cerebral Cortex, Vol. 1. Cellular Components of the Cerebral Cortex, A. Peters and E. G. Jones, eds., pp. 255-308, Plenum, New York.

Magherini, P. C., W. Precht, and P. C. Schwindt (1976) Electrical 
properties of frog motoneurons in the in situ spinal cord. J. Neurophysiol. 39: 459-473.

McCormick, D. A., B. W. Connors, J. W. Lighthall, and D. A. Prince (1985) Comparative electrophysiology of pyramidal and sparsely spiny neurons of the neocortex. J. Neurophysiol. 54.

Moore, J. W., N. Stockbridge, and M. Westerfield (1983) On the site of impulse initiation in a neurone. J. Physiol. (Lond.) 336: 301-311.

Mori, K., M. C. Nowycky, and G. M. Shepherd (1981) Electrophysiological analysis of mitral cells in the isolated turtle olfactory bulb. J. Physiol. (Lond.) 314: 281-294.

Mori, K., M. C. Nowycky, and G. M. Shepherd (1982) Impulse activity in presynaptic dendrites: Analysis of mitral cells in the isolated turtle olfactory bulb. J. Neurosci. 2: 497-502.

Mountcastle, V. B., W. H. Talbot, H. Sakata, and J. Hyvarinen (1969) Cortical neuronal mechanisms in flutter-vibration studied in unanesthetized monkeys. J. Neurophysiol. 32: 452-481.

Northcutt, R. G. (1970) The Telencephalon of the Western Painted Turtle (Chrysemys picta belli), Illinois Biology Monographs, Vol. 43, pp. 1-113, Urbana, IL.

Northcutt, R. G. (1981) Evolution of the telencephalon in nonmammals. Annu. Rev. Neurosci. 4: 301-350.

Ouimet, C. C., and F. F. Ebner (1981) Extrathalamic inputs to the cerebral cortex of the turtle Pseudemys scripta. Anat. Rec. 199: 189A.

Parent, A., and D. Poitras (1974) The origin and distribution of catecholaminergic axon terminals in the cerebral cortex of the turtle (Chrysemys picta). Brain Res. 78: 345-358.

Peters, A. (1971) Stellate cells of the rat parietal cortex. J. Comp. Neurol. 141: 345-374.

Peters, A., and A. Fairen (1978) Smooth and sparsely spined stellate cells in the visual cortex of the cat: A study using a combined Golgielectron microscope technique. J. Comp. Neurol. 181: 129-172.

Purpura, D. P., R. J. Shofer, and T. Scarff (1965) Properties of synaptic activities and spike potentials of neurons in immature neocortex. J. Neurophysiol. 28: 925-942.

Ramon, F., J. W. Moore, R. W. Joyner, and M. Westerfield (1976) Squid giant axons. A model for the neuron soma? Biophys. J. 16: 953-963.

Ramon, P. (1896) El encefalo de los reptiles. Estructura del encefalo del camaleon. Rev. Trim. Micrograf. I (as cited in Ramon y Cajal, 1911).

Ramon y Cajal, S. (1911) Histologie du Système Nerveux de l'Homme et des Vertébrés, Maloine, Paris.

Ribak, C. E. (1978) Aspinous and sparsely-spinous stellate neurons in the visual cortex of rats contain glutamic acid decarboxylase. J. Neurocytol. 7: 461-478.

Ribak, C. E., J. E. Vaughn, and K. Saito (1978) Immunocytochemical localization of glutamic acid decarboxylase in neuronal somata following colchicine inhibition of axonal transport. Brain Res. 140: $315-$ 332.

Romer, A. S. (1972) The Vertebrate Body, W. B. Saunders, Philadelphia.

Scholfield, C. N. (1978) Electrical properties of neurones in the olfactory cortex slice in vitro. J. Physiol. (Lond.) 275: 535-546.

Schwartzkroin, P. A., and L. H. Mathers (1978) Physiological and morphological identification of nonpyramidal hippocampal cell types. Brain Res. 157: 1-10.

Sick, T. J., M. Rosenthal, J. C. Lamanna, and P. B. Lutz (1982) Brain potassium ion homeostasis, anoxia and metabolic inhibition in turtles and rats. Am. J. Physiol. 243: R281-288.

Simpson, J. I. (1976) Functional synaptology of the spinal cord. In Frog Neurobiology. A Handbook, R. Llinas and W. Precht, eds., pp. 728-749, Springer-Verlag, Berlin.

Smith, L. M., F. F. Ebner, and M. Colonnier (1980) The thalamocortical projection in Pseudemys turtles: A quantitative electron microscopic study. J. Comp. Neurol. 190: 445-461.

Spencer, W. A., and E. R. Kandel (1961) Electrophysiology of hippocampal neurons. IV. Fast prepotentials. J. Neurophysiol. 24: 272 285.

Stafstrom, C. E., P. C. Schwindt, J. A. Flatman, and W. E. Crill (1984) Properties of subthreshold response and action potential recorded in layer $\mathrm{V}$ neurons from cat sensorimotor cortex in vitro. J. Neurophysiol. 52: 264-277.

Stewart, W. W. (1978) Functional connections between cells as revealed by dye-coupling with a highly fluorescent naphthalimide tracer. Cell 14: 741-759.

Traub, R. D., and R. Llinás (1979) Hippocampal pyramidal cells: Significance of dendritic ionic conductances for neuronal function and epileptogenesis. J. Neurophysiol. 42: 476-496.

Uchizono, K. (1964) Characteristics of excitatory and inhibitory synapses in the central nervous system of the cat. Nature 207: 642-643.

Ulinski, P. S. (1983) Dorsal Ventricular Ridge: A Treatise on Forebrain Organization in Reptiles and Birds, Wilcy, New York.

Valverde, F. (1970) In Contemporary Research Methods in Neuroanatomy, W. J. H. Nauta and O. E. Ebbesson, eds., pp. 13-31, Springer-Verlag, New York.

Volanschi, D., and Z. Servit (1969) Epileptic focus in the forebrain of the turtle. Exp. Neurol. 24: 137-146.

White, E. L. (1978) Identified neurons in mouse SmI cortex which are postsynaptic to thalamocortical axon terminals: A combined Golgielectron microscopic and degenerative study. J. Comp. Neurol. 181: 627-661. 